\title{
DESENVOLVIMENTO DE ADIANTOPSIS RADIATA, PTERIS DENTICULATA (PTERIDACEAE) E POLYPODIUM LATIPES (POLYPODIACEAE) EM CONDIÇÕES NATURAIS.
}

\author{
Marli A. Ranal ${ }^{2}$
}

Recebido em 10/05/91. Aceito em 18/02/92

RESUMO - Populaçōes de gametófitos e esporófitos de Adiantopsis radiata (L.) Fée, Pteris denticulata Sw. e Polypodium latipes Langsd. et Fisch. ocorrentes em mata mesofítica semidecídua do Estado de São Paulo, Brasil, foram acompanhadas em campodurante 24 meses e amostras coletadas para estudoem laboratório. A morfologia das diferentes fases de desenvolvimento, desde o gametófito até o esporófito adulto, bem como informaçōes relativas ao comportamento das espécies em funçāo de condiçōes de dessecamento são apresentadas.

Palavras-chave: Desenvolvimento heteroblástico, Adiantopsis radiata, Pteris denticulata, Polypodium latipes, Pteridaceae, Polypodiaceae.

ABSTRACT - Populations of gametophytes and sporophytes of Adiantopsis radiata (L.) Fée, Pteris denticulata Sw. and Polypodium latipes Langsd. et Fisch. occurring in a semideciduous mesophytic forest in the State of São Paulo, Brazil, were observed during 24 months and samples were collected for study in the laboratory. The morphology of different phases of development, from gametophytes until the formation of adult sporophytes, as well as informations relative to their behavior in conditions of reduced humidity are presented.

Key Words: Heteroblastic development, Adiantopsis radiata, Pteris denticulata, Polypodium latipes, Pteridaceae, Polypodiaceae.

\section{Introdução}

De um modo geral, os conhecimentos disponíveis sobre pteridófitas, levados em consideração pelos taxonomistas, são baseados em caracteres do esporófito

1. Trabalho financiado pelo CNPq e FAPESP. Parte da tese de doutorado, apresentada na UNESP/ Rio Claro, sob a orientação do Dr. Paulo Günter Windisch.

${ }^{2}$ Universidade Federal de Uberlândia, Departamento de Biociências, Caixa Postal 593, 38400 Uberlândia-MG, Brasil. 
adulto e maduro. É provável que ịsto seja conseqüência do fato dos esporófitos representarem, na maioria dos casos, a fase duradoura do ciclo de vida dessas plantas, o que os torna mais facilmente observados na natureza. Poucas são as espécies em que a fase gametofítica é dominarte, como Actinostachys sp (Bierhorst 1970).

Estudos sobre morfologia comparativa do gametófito e discussões referentes ao valor filogenético dos caracteres desta fase foram apresentados por Stokey (1951), Atkinson \& Stokey (1964) e Atkinson (1973).

Um estudo filogenético das famílias de pteridófitas isosporadas, baseado exclusivamente em caracteres do gametófito, foi apresentado por Nayar \& Kaur (1971). Segundo os autores, as características mais significativas da morfologia do gametófito são o tipo de germinação do esporo, padrão de desenvolvimento, forma do gametófito adulto, natureza dos tricomas e morfologia dos órgãos sexuais. Para alguns grupos, o padrão básico de germinação parece ser um bom caráter taxonômico, conforme demonstraram os trabalhos de Raghavan \& Huckaby (1980) e de Huckaby \& Raghavan (1981a). No entanto, em outros grupos, como dentro do gênero Thelypteris, este não pode ser considerado um bom caráter taxonômico devido à homogeneidade observada entre as espécies (Huckaby \& Raghavan 1981b).

Os questionamentos feitos por vários autores, especialmente no que se refere à plasticidade do gametófito em função das condições ambientais, não permitiram que propostas como a de Nayar \& Kaur (1971) fossem implantadas. Além disso, descrições do gametófito desde a germinação do esporo até a formação dos gametângios ou apenas a descrição do gametófito maduro se restringem a aproximadamente $5 \%$ das espécies, conforme dados obtidos pela autora num levantamento onde foram levados em consideração apenas os materiais identificados a nível de espécie.

Com referência à importância dos caracteres do esporófito jovem para a taxonomia e filogenia das pteridófitas, esta é destacada por vários autores, dentre eles, Bower (1923), Wagner (1952), Rodrigues Rios (1973) e Hennipman (1977). Porém, poucos são os autores que incluem em seus trabalhos discussões dessa natureza e as informações que se tem sobre o desenvolvimento de esporófitos também são bastante restritas. Uma revisão sobre o assunto, feita pela autora, reúne dados sobre 89 espécies, o que representa $1 \%$ das 9000 espécies de pteridófitas encontradas na flora atual.

Estas informações indicam a necessidade de estudos básicos sobre a ontogenia de gametófitos e esporófitos, importantes não só para trabalhos de taxonomia, mas também para trabalhos de levantamento florístico, ecologia e fisiologia que muitas vezes são incompletos ou acabam por ser interrompidos por falta de identificação do material.

No presente trabalho são apresentadas informações referentes à morfologia do gametófito adulto e ao desenvolvimento heteroblástico do esporófito de Adiantopsis radiata (L.) Fée, Pteris denticulata Sw. e Polypodium latipes Langsd. et Fisch., bem como informações relativas ao comportamento das plantas em função de condições de dessecamento. 


\section{Material e Métodos}

As coletas foram feitas em mata mesofítica semidecídua, localizada na Fazenda Barreiro Rico, município de Anhembi, Estado de São Paulo, onde existem três segmentos de mata de 326, 488 e 1386 hectares. O primeiro levantamento de pteridófitas para a escolha das espécies foi feito na área maior, uma vez que trilhas para estudo já estavam delimitadas, constituindo $115 \mathrm{ha}$, conforme mapa e foto aérea apresentados por Assumpção et al. (1982). Este segmento de mata não é cortado por rios e foi encontrado apenas um local mais úmido, com maior número de espécies. Desta forma, o trabalho de campo foi realizado no setor das trilhas, o que permitiu coletas em uma área maior e mais representativa daquele trecho de mata. Nesse local de trabalho, foram encontradas apenas três espécies terrestres, cujo desenvolvimento do esporófito está apresentado neste trabalho.

A região é caracterizada por um clima subtropical úmido, do tipo Cwa (Koeppen 1948), com uma estação seca ocorrendo no inverno que vai de abril a setembro (Ranal 1988). A temperatura média mínima registrada no período de 1970 a 1985 foi de $17,5^{\circ} \mathrm{C}$ no mês de julho e média máxima de $25,2^{\circ} \mathrm{C}$ no mês de fevereiro. A precipitação média anual neste período foi de 1364,1 mm (Ranal 1988).

Durante o puíodo de 1981 a 1986 , foram coletados aproximadamente 120 gametófitos e esporófitos para estudo em laboratório. Odesenvolvimento das plantas também foi acompanhado durante 24 meses em condições de campo (abril de 1984 a maio de 1986). Nesse período de observações, foram marcados gametófitos e esporófitos das três espécies, totalizando 80 indivíduos de Adiantopsis radiata, 51 de Pteris denticulata e 24 de Polypodium latipes. Parte do material foi herborizada e parte, especialmente indivíduos jovens, fixada em cromo-acético fraco I (Sass 1951).

Para a identificação das espécies, foram utilizadas as chaves de identificação e descrições apresentadas por Sota (1960), Tryon (1964a) e Stolze (1981). A nomenclatura adotada está de acordo com o sistema de classificação de Tryon \& Tryon (1982).

Os espécimens testemunho encontram-se depositados no Herbarium Rioclarense (HRCB) do Instituto de Biociências da Universidade Estadual Paulista "Júlio de Mesquita Filho" - Campus de Rio Claro.

Os materiais foram desenhados em estereomicroscópio, comauxílio de câmara clara, ou fotografados. A diafanização para estudos de venação foi feita em solução de $\mathrm{NaOH} 5 \%$.

\section{Resultados e Discussão}

Adiantopsis radiata (L.) Fée, Mém. Fam. Foug. 5 (Gen. Fil.): 145.1852.

Gametófito. O talo adulto e madu ro é reniforme, epigeu, clorofilado, glabro, com arquegônios junto à reentrância apical e anterídios entre os rizóides (Figura 1). Emum dos espécimens coletados foram encontrados anterídios espalhados pelo talo, especialmente na região dos rizóides. 

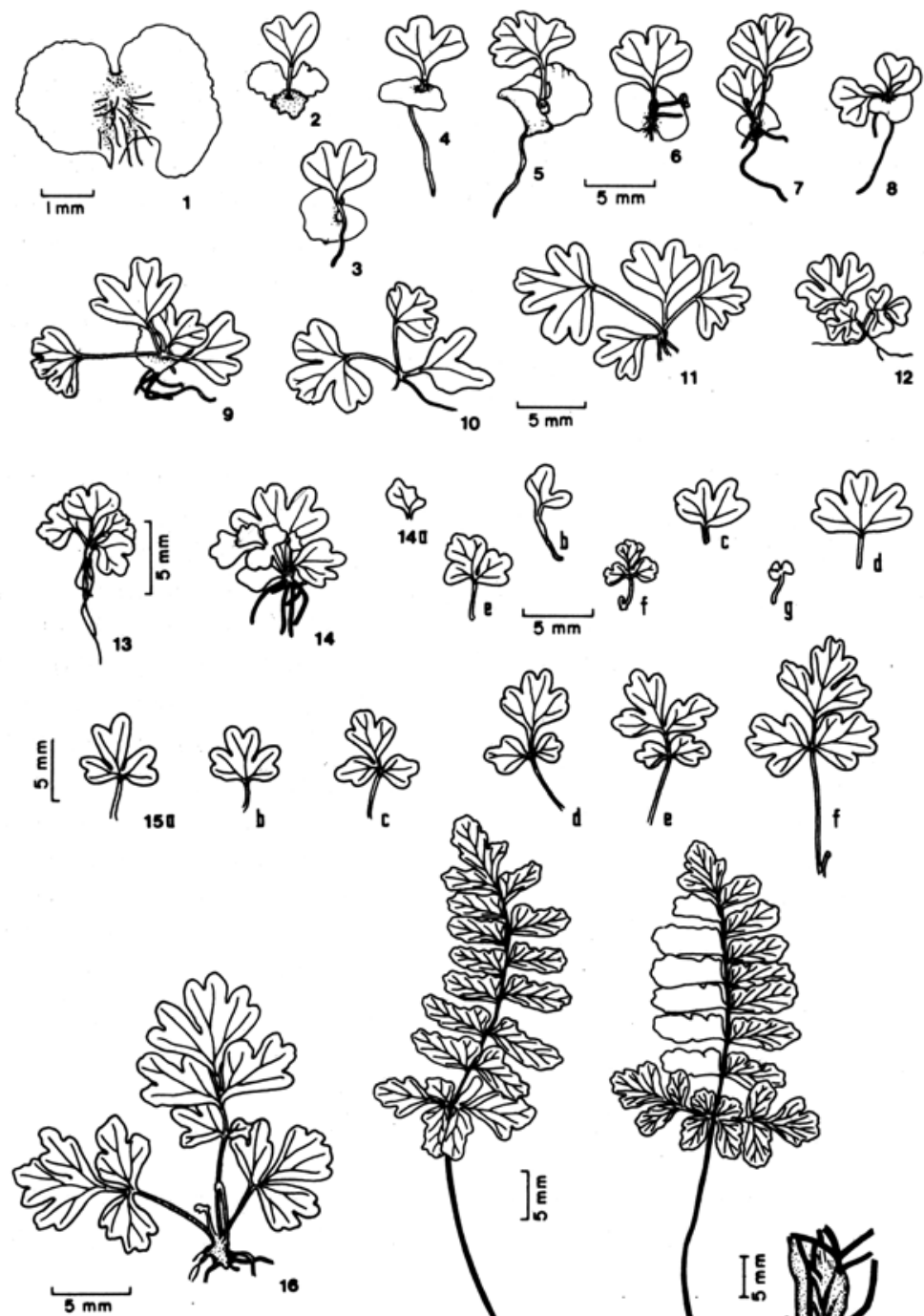

(150
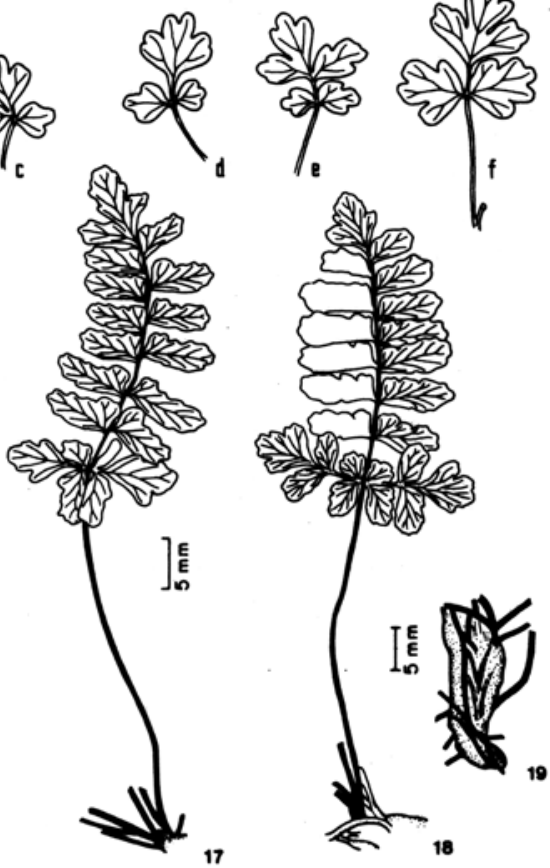

Figuras 1 - 19: Desenvolvimento heteroblástico de Adiantopsis radiata. 1. Gametófito. 2 - 9. Esporófito jovem aderido ao gametófito. 10 - 19. Esporófito jovem. 19. Rizoma de plantas em estádio correspondente ao das figuras 17 e 18. 
Esporófito jovem. As primeiras cinco folhas são flabeliformes, inteiras, bitrilobadas, até lobuladas, sem vena principal, venas ramificadas dicotomicamente, não atingindo a margem da lâmina; base do pecíolo castanho-clara. Plantas com até quatro folhas são encontradas aderidas ao gametófito (Figuras 2-13). Na base do pecíole, desde a primeira folha, aparecem escamas deltóides, castanho-claras (Figuras 22-24, 26). Os báculos encontram-se cobertos por essas escamas, além de tricomas hialinos (Figura 27).

Da sexta-sétima folhas em diante, inicia-se a formação de uma vena principal em folhas pinatipartidas com três segmentos (Figura 14). Até esta fase as plantas apresentam uma raiz por folha. Nos próximos estádios aparecem consecutivamente folhas com o primeiro par de pinas e o ápice pinatífido a pinatipartido; depois folhas com 2-4 pares de pinas, todas com venação livre (Figura 15, 16). Escamas da base do pecíolo de plantas nessa fase estão apresentadas nas Figuras 28 e 31.

A oitava folha apresenta o par de pinas basal com o peciólulo mais alongado em relação às outras pinas e a lâmina com o primeiro par de pínulas diferenciado, iniciando-se assim o estádio bipinado (Figura 17); no próximo estádio aparecem dois pares de pínulas (Figura 18). A lâmina assume a forma trirradiada, sendo o peciólulo preto brilhante como o pecíolo. As folhas nesta fase são longo-pecioladas. Nas fases anteriores o pecíolo é de tamanho variado, indo de curto (menor que metade da folha) a médio (mais ou menos a metade da folha).

À medida que folhas com a lâmina mais complexa vão sendo produzidas, seu pecíolo apresenta-se mais alongado em relação às folhas anteriores, tornando-se de castanho-claro a castanho-escuro, até preto brilhante. As folhas do esporófito jovem são de textura membranácea.

Plantas com seis folhas já possuem um pequeno rizoma, ereto, com algumas escamas. A planta pode produzir cerca de seis folhas trirradiadas. No próximo estádio formam-se mais dois raios na lâmina, na porção basal, e nesse caso as folhas são pentarradiadas (Figura 39). Pínulas no ponto de união das raques estão presentes. A margem das folhas é formada por uma única ca mada de células irregulares, quase sem clorofila (Figuras 21, 29, 30). Tricomas bicelulares recobrem a face adaxial (esparsamente), a face abaxial, a nervura e o pecíolo (Figura 25). Na fase adulta eles são encontrados apenas na face abaxial da lâmina (Figura 32).

Esporófito adulto. Apresenta rizoma ascendente, com escamas inconspícuas. Folhas bipinadas, pinas dispostas radialmente (5-9 pinas), papiráceas; face adaxial glabra e abaxial com tricomas bicelulares; pecíolo longo, $10-55 \mathrm{~cm}$ de comprimento, preto brilhante, glabro na maior extensão de seu comprimento, exceto na base junto ao rizoma onde existem escamas esparsas, caducas; venação livre, com algumas venas espessadas na extremidade (Figura 20). Soros marginais descontínuos, indúsio formado pela margem das pínulas, modificada e retroflexa; esporos triletes.

Nas Figuras 33-40 está apresentada a seqüência de desenvolvimento heteroblástico da espécie, baseada em material herborizado. 


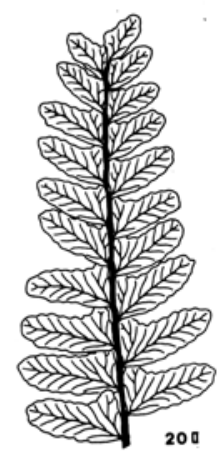

8$$
200
$$

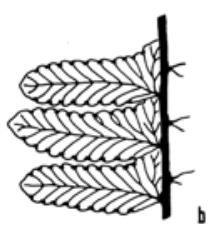

$$
5 \mathrm{~mm}
$$
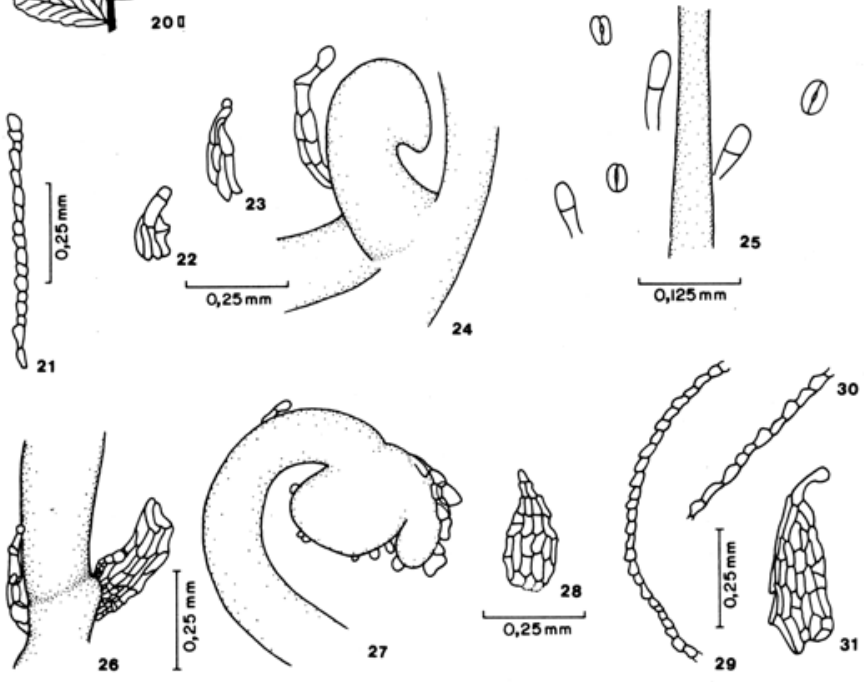

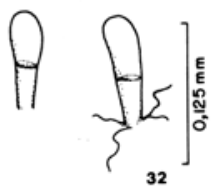

Figura 20: Esporófito adulto de Adiantopsis radiata, pina de uma folha fértil. a. Porçāo apical. b. Porção mediana. c. Porção basal.

Figuras 21-32: Indumento das folhas e rizoma dos esporófitos. 21. Células da margem da folha do esporófito jovem. 22-24. Escamas da base do pecíolo da planta representada na figura 3. 25. Tricomas da face abaxial da lâmina foliar da planta representada na figura 3. 26. Escamas da base do pecíolo da planta representada na figura 7. 27. Báculo com tricomas; planta representada na figura 7. 28-31. Da planta representada na figura 15.28, 31. Escamas da base do pecíolo. 29,30. Células da margem da lâmina foliar. 32. Tricomas da face abaxial da lâmina foliar do esporófito adulto. 


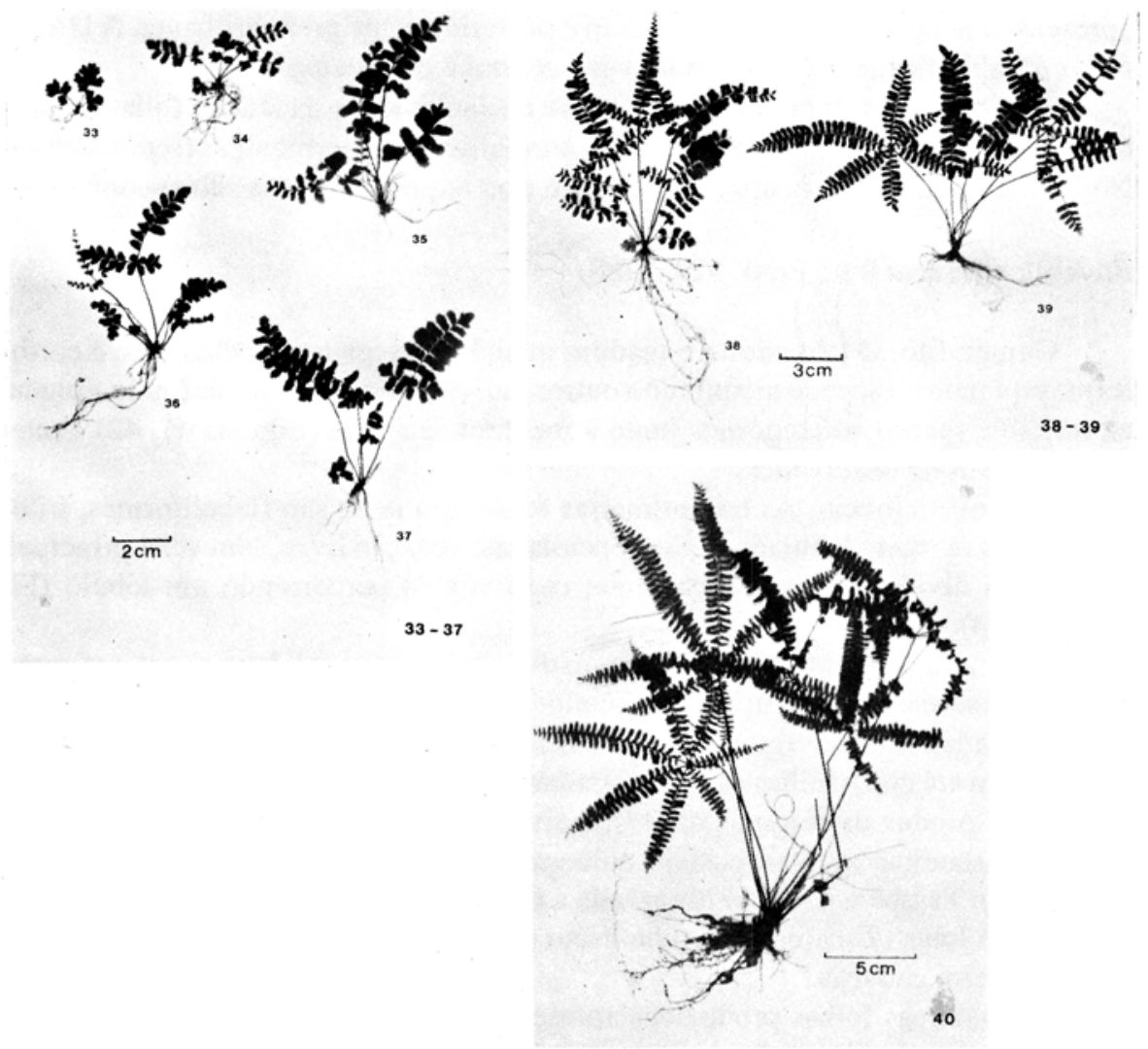

Figuras 33-40: Desenvolvimento heteroblástico deAdiantopsis radiata. 33-39. Esporófitos jovens. 40. Esporófito adulto, fértil.

Hábitat. Gametófitos e esporófitos jovens são encontrados em pontos mais iluminados da mata e onde o substrato não está colonizado por outras plantas, tais como barrancos da margem de picadas e troncos em decomposição localizados em clareiras. Na maioria dos casos, os gametófitos foram encontrados com a reentrância apical voltada para baixo, em relação ao solo. Foi localizada uma população de esporófitos ainda jovens com folhas radiadas, crescendo na base de tronco de árvore, até $7 \mathrm{~cm}$ acima do nível do solo, local com acúmulo de matéria orgânica e uma inclinação que não difere muito da situação encontrada em troncos caídos ou barrancos.

Esporófitos adultos são terrestres, encontrados mais freqüentemente crescendo diretamente sobre o solo ou ainda sobre troncos em decomposição.

Observações. Esporófitos jovens dessa espécie são facilmente distinguidos por 
apresentarem pecíolo castanho no início e posteriormente preto brilhante. A lâmina foliar é flabeliforme, desprovida de vena central e de escamas.

Espécie que apresenta acentuado grau de deciduidade da lâmina foliar durante o período seco. Inicialmente as pínulas se enrolam e posteriormente sofrem abscisão. No final do período seco, apenas o pecíolo e as raques das pinas são encontrados.

Pteris denticulata Sw., Prod. 129. 1788.

Gametófito. $\mathrm{O}$ talo adulto e maduro quando crescendo isoladamente é cordiforme e quando crescendo misturado a outros indivíduos, sem forma definida, epigeu, clorofilado, glabro; arquegônios junto à reentrância apical (Figuras 41, 42). Anterídios não foram observados.

Esporófito jovem. As três primeiras folhas em geral são flabeliformes, trilobadas, com margem lobulada, longo-pecioladas, venação livre, sem vena principal, com venas divididas dicotomicamente; cada vênula percorrendo um lóbulo (Figuras 41-44).

Da quarta folha em diante, o número de lóbulos aumenta, bem como o número de dicotomias das venas; o ápice dos lóbulos, em folhas produzidas sucessivamente, torna-se gradativamente agudo, até que a margem da lâmina foliar se torne denteada. Plantas com até cinco folhas são encontradas aderidas ao gametófito; uma única raiz por folha é produzida (Figuras 45-47); textura membranácea.

As primeiras aréolas costais começam a aparecer a partir da nona folha (Figura 48). Também pode ser observada a presença de uma vena principal em cada um dos três lobos. Escamas castanho-escuras aparecem no pecíolo e rizoma, sendo as do primeiro caducas.

As próximas folhas produzidas apresentam a margem serreada, os três lobos completamente divididos, formando o primeiro par de pinas basais (Figura 61); no próximo estádio os lobos basais são pinatífidos e o lobo apical, inteiro (Figuras 62, 63). As folhas produzidas posteriormente apresentam o lobo apical pinatífido a pinatipartido, iniciando-se a formação do segundo par de pinas (Figura 64). O pecíolo, próximo à lâmina foliar, é alado. Escamas do pecíolo e rizoma da planta representada na Figura 64 encontram-se nas Figuras 50 a 52.

As Figuras 54-65 representam a seqüência de desenvolvimento heteroblástico da espécie, baseada em material herborizado.

Esporófito adulto. Apresenta rizoma ascendente, com escamas inconspícuas (Figura 53). Folhas pinadas, pinatífidas na base, deltóides, papiráceo-herbáceas, margens estéreis serreado-espinescentes, face adaxial da lâmina com tricomas tricelulares simples junto à vena principal das pinas, face abaxial com tricomas bicelulares ou tricelulares simples, esparsos, por toda a lâmina; pecíolo longo 1/2$1 / 3$ do tamanho total da folha, com escamas caducas. Venação anastomosada, sem vênulas incluídas; venas livres acima das aréolas, com espessamento na extremidade (Figura 49). Soros marginais contínuos, indúsio membranoso formado pela margem das pinas, modificada e retroflexa; esporos triletes (Figuras 65, 66). 

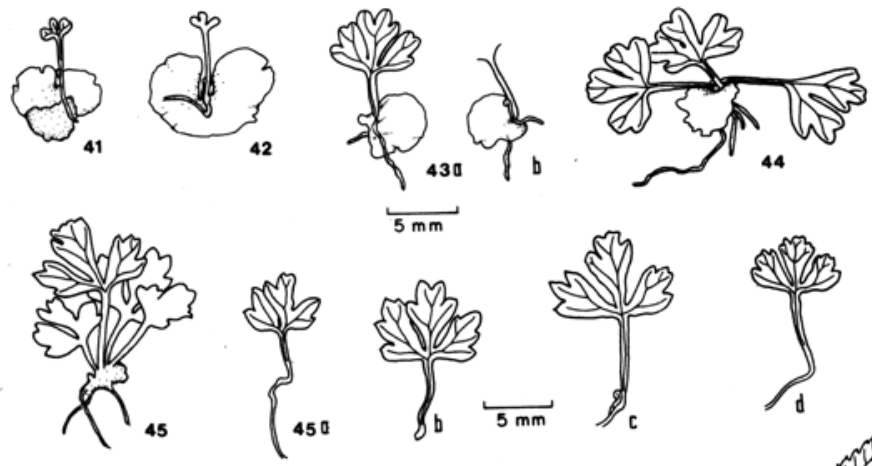

$$
5 \mathrm{~mm}
$$
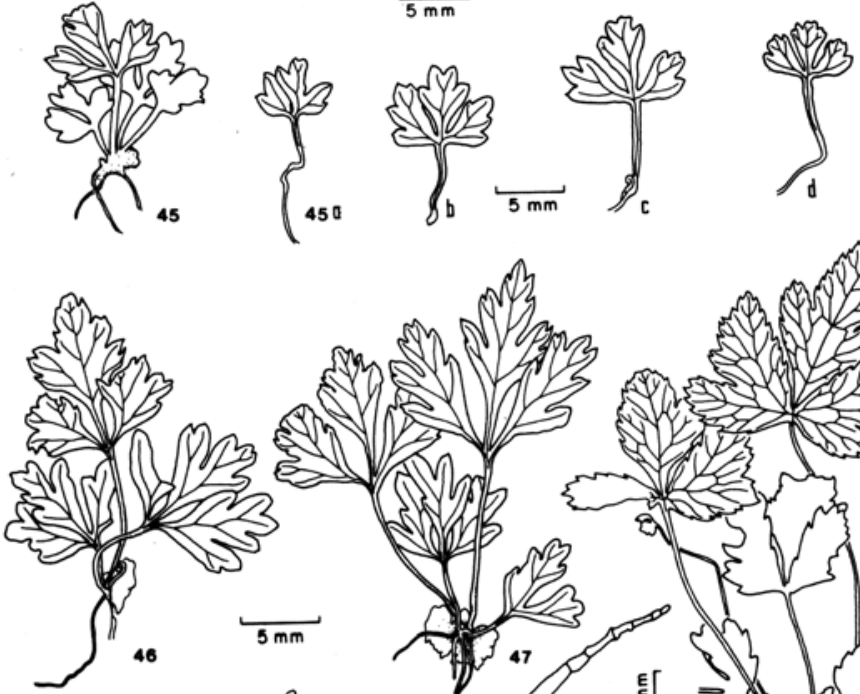

d
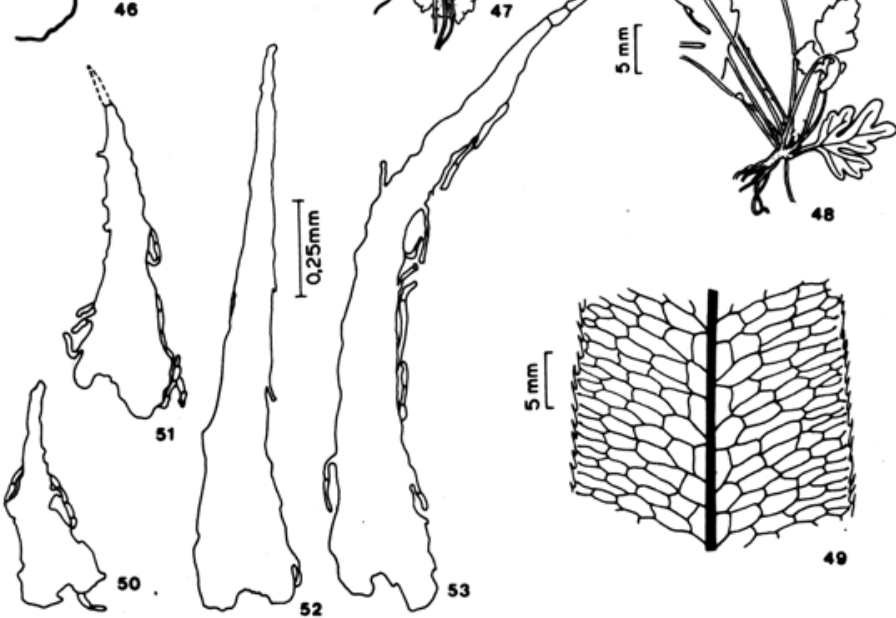

Figuras 41-49: Desenvolvimento heteroblástico de Pteris denticulata. 41-47. Esporófito jovem aderido ao gametófito. 48. Esporófito jovem. 49. Esporófito adulto; regiāo mediana de uma pina.

Figuras 50-53: Escamas do pecíolo e rizoma dos esporófitos. 50-51. Escamas do rizoma da planta representada na figura 64. 52. Escama do pecíolo da mesma planta. 53. Escama do rizoma da planta adulta. 

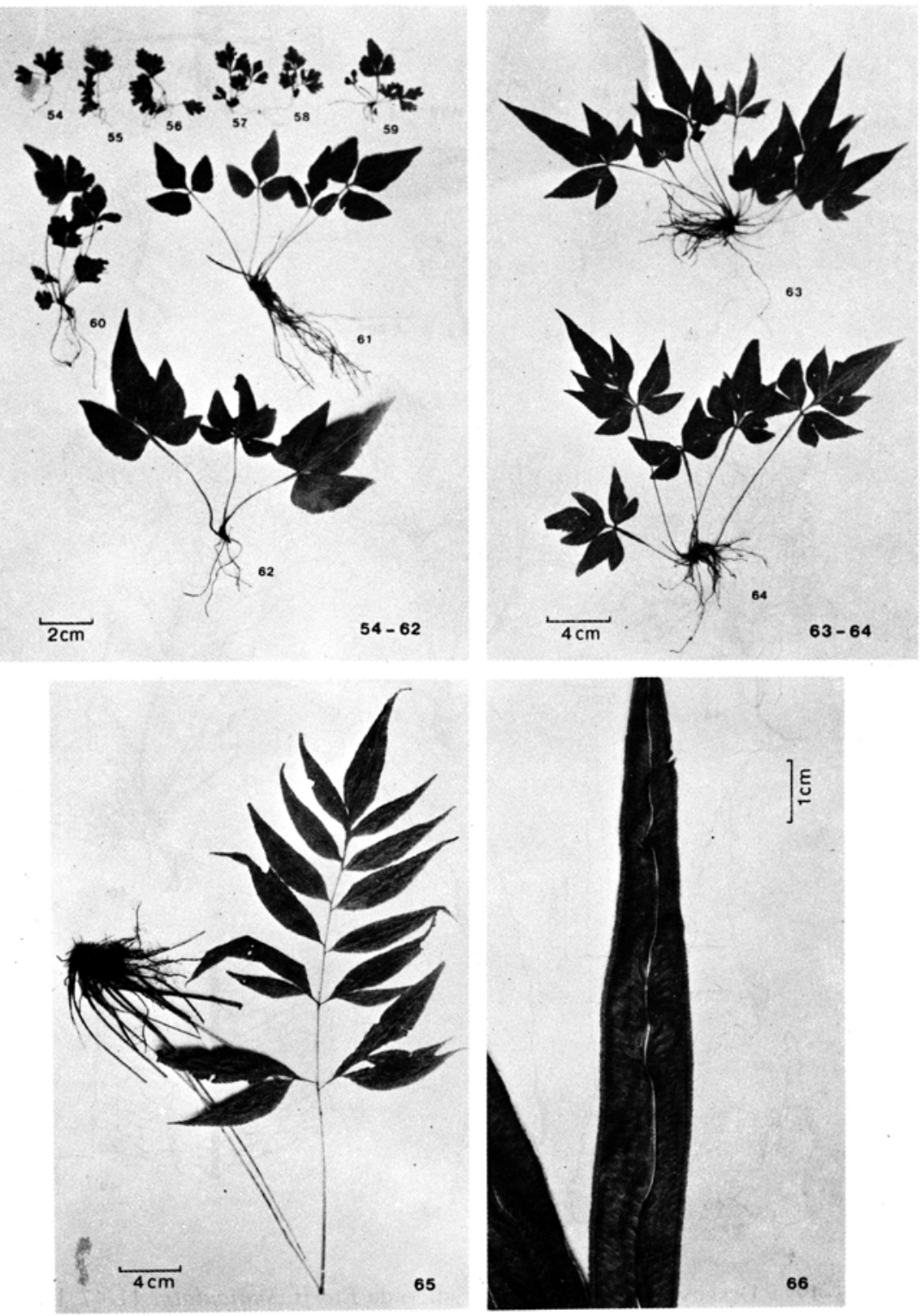

Figuras 54-66: Desenvolvimento heteroblástico de Pteris denticulata. 54-64. Esporófitos jovens. 65. Esporófito adulto, estéril. 66. Detalhe de uma folha fértil. 
Hábitat. Gametófitos e esporófitos jovens são encontrados em geral sobre troncos em decomposição, ainda não colonizados por outras plantas, localizados em pontos mais sombrios da mata. Esporófitos adultos são terrestres, encontrados crescendo diretamente sobre o solo ou sobre troncos em decomposição, em locais mais sombrios da mata ou mais iluminados, tais como margem de picadas.

Observações. Esporófitos jovens dessa espécie são distinguidos daqueles de Adiantopsis radiata pelo pecíolo claro e pelas margens da lâmina que apresentam lóbulos com ápice mais agudo.

Plantas jovens de locais mais protegidos e plantas adultas, mesmo quando crescendo em pequenas cla reiras naturais, sobrevivemà seca sem que ocorra abscisão foliar. As plantas jovens de locais menos protegidos murcham e secam irreversivelmente.

Polypodium latipes Langsd. et Fisch., Ic. Fil.: 10. 1810.

Gametófito. Otalo adulto e maduro apresenta-se cordiforme, epigeu, clorofilado, com tricomas papilados unicelulares, esparsos na margem e fa-ce ventral; face dorsal glabra (Figuras 67,78). Emalguns espécimens foram encontrados tricomas bicelulares, próximos aos arquegônios (Figura 79).

Dos espécimens examinados, foram encontrados indivíduos apenas arquegoniados, apenas anteridiados e também aqueles comos dois tipos de gametângios ocorrendo misturados na região central do talo.

Esporófito jovem. As duas primeiras folhas são espatuliformes, inteiras, com uma vena simples não atingindo a margem ou com uma vena ramificada dicotomicamente; curto-pecioladas, margem ondulada com tricomas unicelulares esparsos; ambas as faces da lâmina foliar e o pecíolo também apresentam tricomas unicelulares ou tricelulares ramificados (Figuras 68, 69, 80, 81). Nesta fase, escamas da base do pecíolo estão em formação (Figuras 69, 82). Algumas plantas nesta fase apresentam folhas flabeliformes, margem lobada, venação livre com vena principal; pecíolo 1/3-1/4 do comprimento da folha; margem da lâmina com tricomas bicelula res; face adaxial, abaxial e pecíolo com tricomas tricelulares ramificados (Figuras 70, 83, 84). As margens da lâmina são formadas por uma única fileira de células retangulares (Figuras 81,83 ). Foi observada uma única raiz por folha.

Um pequeno rizoma começa a ser diferenciado em plantas com 3-5 folhas. Estas são mais ou menos flabeliformes, lobadas, com vena principal, com pecíolo 1/2-1/ 3 do comprimento da folha (Figura 71). Lâmina e pecíolo são recobertos por tricomas bicelu lares, raros unicelulares. Partes do tecido gametofítico são encontradas até esta fase.

Num estádio mais avançado do desenvolvimento são produzidas folhas pinatilobadas assimétricas, com vena principal (Figura 72). Escamas estão presentes na base do pecíolo (Figura 85). Estas são clatradas, lanceoladas, ápice acuminado, curvado, basipeltadas, com margem ondulada. $O$ ápice dos báculos é densamente 


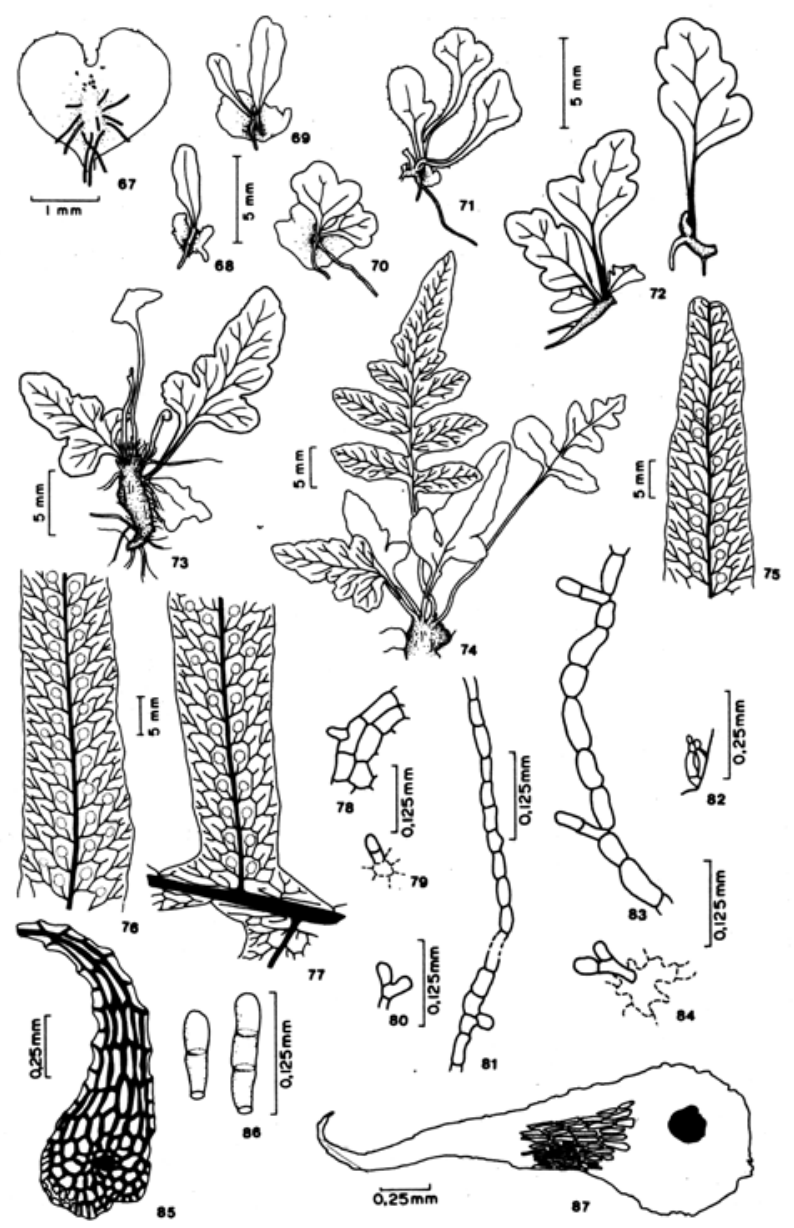

Figuras 67-77: - Desenvolvimento heteroblástico de Polypodium latipes. 67. Gametófito. 68-71. Esporófito jovem aderido ao gametófito. 7-74. Esporófito jovem. 75-77. Segmento de folha fértil do esporófito adulto. 75. Porçāo apical. 76. Porçāo mediana. 77. Porçāo basal. Figuras 78-87: Indumento do gametófito, das folhas e rizoma de esporófitos da espécie. 78. Células da margem do gametófito. 79. Tricoma da face ventral do gametófito, junto aos arquegônios. 80-82. Da planta representada na figura 69. 80. Tricoma da face abaxial da lâmina foliar. 81. Células da margem da lâmina foliar. 82. Escamas da base do pecíolo.8384. Da planta representada na Figura 70.83. Células da margem da lâmina foliar. 84. Tricoma da face abaxial da lâmina foliar. 85. Escama da base do pecíolo; planta representada na figura 7.86. Tricomas da face abaxial da lâmina foliar da planta adulta. 87. Escama do rizoma da planta aduita. 
coberto por tricomas tricelulares ramificados e bicelulares unisseriados. Tricomas similares a estes também estão presentes na lâmina foliar e pecíolo.

Um rizoma escamoso e bastante evidente é encontrado em plantas com folhas deltóides, pinatilobadas a pinatífidas (Figura 73). Até esta fase, aréolas não se formaram; a venação é livre, com vena principal. Folhas pinatipartidas a pinatissectas similares às do esporófito adulto são produzidas posteriormente (Figuras 74,91, 92). Nesta fase, as primeiras aréolas costais com uma vênula incluída livre são produzidas, primeiro na pina apical e posteriormente nas demais pinas, em folhas diferentes. Tricomas unicelulares a tricelulares, unisseriados, estão presentes nas faces adaxial e abaxial da lâmina foliar, sendo mais abundantes na margem e esparsos no pecíolo.

A textura das folhas varia de membranácea, nas formas mais jovens, a papirácea nas mais velhas.

Esporófito adulto. A planta adulta apresenta rizoma rastejante, com escamas (Figura 87). As folhas são deltóides, pinatipartidas a pinatissectas, papiráceas; lâmina com faces adaxial e abaxial apresentando tricomas uni a tricelulares, unisseriados, sendo mais freqüentes na face abaxial (Figura 86); pecíolo longo, 1/2-1/3 do tamanho total da folha, com escamas esparsas e caducas na região basal. Soros dorsais, circulares, localizados terminalmente em vênulas incluídas, maioria livres, algumas anastomosadas, distribuídos em uma única fileira em cada lado da vena principal na região basal e apical do segmento e em duas fileiras na região mediana deste, sem indúsio; esporos monoletes. Venação gonioflebóide, com uma a duas fileiras de aréolas de cada lado da vena principal; venas livres acima das aréolas, espessadas na extremidade (Figuras 75-77).

Nas Figuras 88-93 está apresentada a seqüência de desenvolvimento heteroblástico da espécie, baseada em material herborizado.

Hábitat. Gametófitos e esporófitos jovens são encontrados em barrancos, diretamente sobre o solo e sobre troncos em decomposição. Foi registrada a ocorrência de um esporófito, até a fase correspondente à da Figura 74, na base de tronco de árvore (Ocotea aff. spixiana (Nees.) Mez., Lauraceae, “canelão”), cerca de $30 \mathrm{~cm}$ acima do nível do solo. Poucos gametófitos e esporófitos jovens foram encontrados e, em geral, as fases mais jovens ocorrem em pontos do substrato livres de outras plantas, até mesmo de pequenas briófitas. A reentrância apical do talo do gametófito geralmente encontra-se voltada para baixo em relação ao solo.

$\mathrm{O}$ esporófito adulto é terrestre, crescendo mais freqüentemente sobre solo e mais raramente sobre troncos em decomposição.

Observações. Espécie relativamente resistente à seca, mantendo suas folhas verdes durante parte do período seco. Posteriormente tornam-se desidratadas e enroladas até ocorrer abscisão. $O$ rizoma carnoso das plantas permanece intacto sob o solo, produzindo novas folhas quando começa o período de chuvas. 

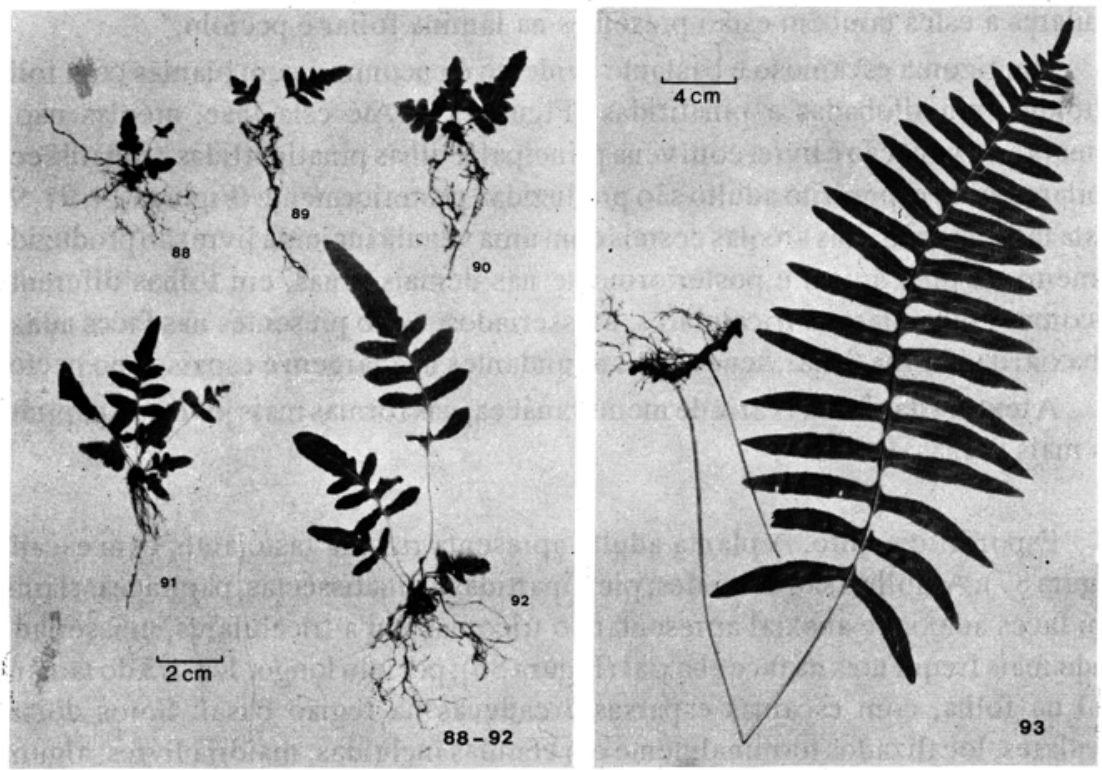

Figuras 88-93: Desenvolvimento heteroblástico de Polypodium latipes. 88-92. Esporófitos jovens. 9Z. Esporófito adulto, estéril.

Por mais antigos que sejam, os trabalhos referentes à morfologia da fase gametofítica são baseados em materiais mantidos em cultura pura, em condições de laboratório. Poucas são as espécies cujos gametófitos crescendo em condições natura is são descritos. Dentre os trabalhos examinados, podem ser citados aqueles de espécies com gametófito subterrâneo, de crescimento lento, como Botrychium (Bruchmann 1906; Campbell 1921, 1922; Nozu 1954; Nishida 1955; Bierhorst 1958) e outros de espécies com gametófito epigeu como Lygodium volubile Sw.(Dias Filha 1989), Microgramma lindbergii (Mett.) Sota (Ranal no prelo), Plagiogyria fialhoi (Fée et Glaz.) Cop.(Windisch \& Pereira-Noronha 1983), Polypodium pleopeltifolium Raddi, $P$. polypodioides (L.) Watt. (Ranal no prelo) e Trichomanes pilosum Raddi (Sehnem 1965), todos eles restritos a descrições do talo adulto.

A dificuldade para se encontrar gametófitos jovens na natureza e a incerteza da espécie à qual eles pertencem, mesmo quando coletados na fase adulta, talvez sejam os dois grandes impedimentos que não permitem a inclusão dessas informações nos trabalhos. Segundo Stokey (1951), o alto grau de plasticidade do gametófito, tão vantajoso para o estabelecimento de uma espécie no ambiente, representa uma dificuldade para o coletor, uma vez que o gametófito é capaz, por exemplo, de crescer como um filamento ou uma fita quando a intensidade luminosa é baixa, até atingir 
algum ponto do substrato em que a intensidade luminosa é maior. A manutenção da fase filamentosa, não só em decorrência da baixa intensidade luminosa, mas também em altas temperaturas e em culturas densas, foi verificada por Ranal (1983) para oito espécies da mata da Fazenda Barreiro Rico, incluindo as três cujo desenvolvimento do esporófito está sendo apresentado. Isso indica o grau de dificuldade da coleta desse material que pode ser confundido com hepáticas e protonemas de musgos.

Em função disso, apenas os gametófitos aderidos aos seus esporófitos e gametófitos adultos similares àqueles aderidos aos esporófitos foram levados em consideração para as descrições e sua morfologia foi comparada coma dos ga metófitos obtidos em culturas puras de laboratório. Qualquer trabalho com descrições de gametófitos baseadas apenas em coletas de campo, sem trabalho de laboratório para confirmação, devem ser estudados com reserva.

Dificuldade maior é enfrentada quando se trabalha com grupos que apresentam gametófitos adultos caracteristicamente filamentosos, comoé o caso de Trichomanes e Schizaea ou em forma de fita como Elaphoglossum e Rhipidopteris, dentre outros (Nayar \& Kaur 1971).

Nos primeiros estádios de desenvolvimento, as folhas de Adiantopsis radiata e Pteris denticulata são flabeliformes, lobadas, com venação livre, dicotômica, sem vena principal, características estas típicas de folhas do tipo "sem vena principal", descrito por Wagner (1952). Esse mesmo tipo de folha tem sido observado em esporófitos jovens de pteridófitas arborescentes (Stephenson 1907; Lucansky \& White 1976), em Athyrium esculentum Cop. (Nayar 1960), em espécies de Blechnum (Rodrigues Rios 1973), de Bolbitis (Hennipman 1977), em Plagiogyria fialhoi (Windisch \& Pereira-Noronha 1983), dentre outras. Esporófitos de Polypodium latipes no início do desenvolvimento são caracterizados pela presença de folhas espatuliformes ou flabeliformes, com venação livre e vena principal. A presença de uma vena principal também caracteriza o desenvolvimento de Microgramma lindbergii, Polypodium pleopeltifolium e P. polypodioides (Ranal no prelo). Segundo Wagner(1952), a maior parte das espécies de pteridófitas tem folhas jovens sem vena principal, mesmo que na fase adulta esta seja evidente. Seria interessante rever esta informação de Wagner quando maior número de espécies tiver seu desenvolvimento estudado.

Com referência à morfologia da folha do esporófito adulto, Pteris denticulata e Polypodium latipes podem ser incluídas no tipo pinado-determinado de Tryon (1964b). Adiantopsis radiata tem folhas radiadas, com as pinas da lâmina partindo do mesmo ponto em vários raios. O primeiro tipo é o mais comum, estando presente em aproximadamente $85 \%$ das espécies de Filicopsida e o tipo radiado mais raro (Tryon 1964b).

Quanto ao pad rão sazonal de crescimento e dormência te Kornás, 1978 (Kornás 1985), Adiantopsis radiata pode ser considerada uma espécie do tipo decíduo, verde no verão. Segundo Kornás (1985), esse tipo constitui cerca de $40 \%$ da flora pteridofítica de Zâmbia e parece ser particularmente bem adaptado à sazonalidade do clima seco. Cheilanthes tenuifolia (Burm.) Sw. e C. sieberi Kunze (Pteridaceae) 
da Austrália sobrevivem durante os meses de verão na forma de rizoma, enquanto as folhas morrem e caem completamente (Quirk \& Chambers 1981).

Espécimens de Polypodium latipes, quando submetidos a condições severas de dessecamento, também perdem suas folhas, mas não com tanta regularidade quanto Adiantopsis radiata, podendo ser considerada uma espécie com comportamento intermediário entre o tipo decíduo verde no verão e o sempre-verde.Pterisdenticulata pode ser incluída no tipo sempre-verde, pois não apresenta periodicidade sazonal quanto à produção de folhas. Kornás (1985) também encontrou uma espécie do mesmo gênero em Zâmbia, Pteris friesii Hieron, incluída nesse tipo. Segundo Gams em 1938, o hábito sempre-verde tem sido reconhecido como evolutivamente primitivo em pteridófitas que aparentemente se originaram sob condições de clima tropical úmido. Segundo o mesmo autor, o hábito poiquilohíd rico e o decíduo verde no verão, parecem representar adaptações alternativas para colonizar hábitat sazonalmente secos (Kornás 1985).

Observações sobre enrolamento de folha como resposta a estresse hídrico foram registradas para Polypodium angustum (H.B. Willd.) Liebm. (Accorsi 1941a), para $P$. lepidopteris (Langsd. et Fisch.) Kunze (Accorsi 1941b) e para $P$. polypodioides (Accorsi 1941c).

Na flora epífita da Serra do Mar do Paraná, Hertel(1950)encontrou apenas entre as Polypodiaceae plantas suportando condições de dessecamento e retomando suas funções vegetativas por ocasião da primeira chuva. As folhas de Polypodium astrolepis Liebm. e $P$. lepidopteris permanecem secas durante tempo relativamente longo, sem que ocorra abscisão foliar. Esse tipo poiquilohídrico, com crescimento ativo durante o período chuvoso e dormência na seca com as folhas enroladas, representa $20 \%$ da flora pteridofítica de Zâmbia, a maioria das espécies ocorrendo como epífitas ou sobre rochas (Kornás 1985).

As famílias Pteridaceae e Polypodiaceae são consideradas, no sistema de classificação de Tryon \& Tryon (1982), como evoluídas, sendo que dentre as duas, Pteridaceae reúne maior número de caracteres considerados primitivos e Polypodiaceae maior número de caracteres evoluídos.

Dentre as características apresentadas neste trabalho, podem ser destacadas como primitivas, a venação aberta presente em Adiantopsis radiata desde as fases mais jovens até o indivíduo adulto e em Pteris denticulata e Polypodium latipes apenas nas fases jovens; folhas do tipo pinado-determinado que caracterizam o esporófito adulto de Pteris denticulata e Polypodium latipes; soros com indúsio constituído pela margem da lâmina retroflexa em Adiantopsis radiata e Pteris denticulata; esporos triletes presentes em Adiantopsis radiata e Pteris denticulata; padrão sazonal de crescimento sempre-verde em Pteris denticulata.

Como evoluídas, podem ser destacadas a venação anastomosada presente em Pteris denticulata de forma mais simples e em Polypodium latipes mais complexa; folhas do tipo radiado em Adiantopsis radiata, com muitos segmentos de última ordem, pequenos e articulados, características estas adaptativas a hábitat sazonalmente secos; soros sem indúsio e esporos monoletes em Polypodium latipes; padrão 
sazonal de crescimento decíduo verde no verão em Adiantopsis radiata; pecíolo articulado em Polypodium latipes.

Levando-se em consideração as informações obtidas para Microgramma lindbergii, Polypodium pleopeltifolium e $P$. polypodioides (Ranal no prelo), podese acrescentar como caracteres evoluídos o hábito epífita e o indumento densamente escamoso de folhas e rizoma que caracteriza essas três Polypodiaceae. Segundo Sota (1973), os poucos representantes terrestres de Polypodiaceae provavelmente derivaram de ancestrais epífitas.

As informações aqui reunidas indicam a proximidade das duas famílias, mas não constituem subsídio suficiente para uma discussão mais profunda sobre a filogenia das mesmas, o que só poderá ocorrer quando maior número de espécies tiver seu desenvolvimento conhecido.

\section{Agradecimentos}

A autora agradece ao Dr. David G. Francis pela revisão do "Abstract".

\section{Referências Bibliográficas}

ACCORSI, W.R. 1941a. Observações sobre a defesa do Polypodium angustum (H.B. Willd.) Liebm., em relação ao fator água. Rev. Agric. 16(5/6): 254-262.

ACCORSI, W.R. 1941b. Observações sobre a defesa do Polypodium lepidopteris Kunze, em relação ao fator água. Rev. Agric. 16(7/8): 362-369.

ACCORSI, W.R. 1941c. Observações sobre a defesa do Polypodium polypodioides (L.) Hitchcock em relação ao fator água. Rev. Agric. 16(3/4): 185-197.

ASSUMPÇÃO, C.T.; H.F. LEITÃO FILHO \& O. CESAR. 1982. Descrição das matas da Fazenda Barreiro Rico, Estado de São Paulo. Rev. Bras. Bot. 5: 53-66.

ATKINSON, L.R. 1973. The gametophyte and family relationships. In Jermy, A.C.; J.A. Crabbe \& B.A. Thomas, (ed.) The phylogeny and classification of the ferns. Academic Press. London. p. 73-90.

ATKINSON, L.R. \& A.G. STOKEY. 1964. Comparative morphology of the gametophyte of homosporous ferns. Phytomorphology 14(1): 51-70.

BIERHORST, D.W. 1958. Observations on the gametophytes of Botrychium virginianum and B. dissectum. Am. J. Bot. 45(1): 1-9.

BIERHORST, D.W. 1970. A vascular plant with a dominant gametophyte: Actinostachys sp. Am. J. Bot. 57(6) part 2: 744.

BOWER, F.O. 1923. The ferns (Filicales): treated comparatively with a view to their natural classification. 1. Analytical examination of the criteria of comparison. Today \& Tomorrow's Book Agency. New Delhi. v.1. 359p.

BRUCHMANN, H. 1906. Über das prothallium und die sporenplanze von Botrychium lunaria. Flora 96: 203-230. 
CAMPBELL, D.H. 1921. The gametophyte and embryo of Botrychium obliquum Muhl. Ann. Bot. 35: 141-156.

CAMPBELL, D.H. 1922. The gametophyte and embryo of Botrychium simplex Hitch. Ann. Bot. 36: 441-455.

DIAS FILHA, M.C.C. 1989. Aspectos fenológicos e germinação de esporos de Lygodium volubile Sw. (Schizaeaceae). Dissertação de Mestrado, Universidade Federal de Pernambuco, Recife. 124p.

HENNIPMAN, E. 1977.A monograph of the fern genusBolbitis(Lomariopsidaceae). Leiden University Press. Leiden. 331p.

HERTEL, R.J.G. 1950. Contribuição à ecologia da flora epífita da Serra do Mar (Vertente Oeste) da Paraná. Arch. Mus. Parana. 8: 1-63.

HUCKABY, C.S. \& V. RAGHAVAN. 1981a. Spore germination patterns in the ferns, Cyathea and Dicksonia. Ann. Bot. 47(3): 297-403.

HUCKABY, C.S. \& V. RAGHAVAN. 1981b. The spore-germination pattern of Thelipteroid ferns. Am. J. Bot. 68(4): 517-523.

KOEPPEN, W. 1948. Climatologia: con un estudio de los climas de la Tierra. Trad P.R. Hendrichs Pérez. Fondo de Cultura Economica. Mexico. p.152-182.

KORNÁS, J. 1985. Adaptive strategies of African pteridophytes to extreme environments. In A.F. Dyer \& C.N. Page, (ed.) Biology of pteridophytes. The Royal Society of Edinburgh. Endinburgh. p. 391-396.

LUCANSKY, T.W. \& R.A. WHITE. 1976. Comparative ontogenetic studies in young sporophytes of tree ferns. I. A primitive and an advanced taxon. Am.J. Bot. 63(4): 463-472.

NAYAR, B.K. 1960. The gametophyte and young sporophyte of Athyrium esculentum. Am. Fern J. 50(2): 194-203.

NAYAR, B.K. \& S. KAUR. 1971. Gametophytes of homosporous ferns. Bot. Rev. 37(3): 295-396.

NISHIDA, M. 1955. The morphology, gametophyte, young sporophyte and systematic position of Botrychium japonicum Und. Phytomorphology (5): 449-456.

NOZU, Y. 1954. The gametophyte and sporophyte of Botrychium japonicum Und. Phytomorphology 4: 430-434.

QUIRK, H. \& T.C. CHAMBERS. 1981. Drought tolerance in Cheilanthes with special reference to the gametophyte. Fern Gaz. 12(3): 121-129.

RAGHAVAN, V. \& C.S. HUCKABY. 1980. A comparative study of cell division patterns during germination of spores of Anemia, Lygodium and Mohria (Schizaeaceae). Am.J.Bot. 67(5): 653-663.

RANAL, M.A. 1983. Efeito da temperatura e da intensidade luminosa no desenvolvimento de gametófitos de pteridófitas. Dissertação de Mestrado, Universidade Estadual Paulista "Júlio de Mesquita Filho", Rio Claro. 234p.

RANAL, M.A. 1988. Estabelecimento e desenvolvimento da geração esporofítica de pteridófitas em mata seca semidecídua do Estado de São Paulo. Tese de 
Doutorado, Universidade Estadual Paulista "Júlio de Mesquita Filho", Rio Claro. 217p.

RANAL, M.A. (no prelo). Desenvolvimento de Polypodium pleopeltifolium Raddi, Polypodium polypodioides (L.) Watt. e Microgramma lindbergii (Mett.) Sota (Polypodiaceae) em condições naturais. Hoehnea 18(2).

RODRIGUES RIOS, R. 1973. Morfologia de los protalos y esporofitos jovenes de algunas especies chilenas de Blechnum (Polypodiaceae s.l.) Gayana. Botanica (22): 1-17.

SASS, J.E. 1951. Botanical microtechnique. 2nd. ed. The Iowa State College Press. Iowa. $227 \mathrm{p}$.

SEHNEM, A. 1965. Observações sobre o protalo de Trichomanes pilosum Raddi. Pesquisas - Botânica, Porto Alegre 19: 1-5.

SOTA, E.R. 1960. Polypodiaceae y Grammitidaceae argentinas. Opera Lilloana 5: 1-229.

SOTA, E.R.1973. On the classification and phylogeny of the Polypodiaceae.In A.C. Jermy; J.A. Crabbe \& B.A. Thomas, (ed.) The phylogeny and classification of the ferns. Academic Press. London. p. 229-244.

STEPHENSON, G.B. 1907. Young stages of Dicksonia and Cyathea. Trans. N. Z. Inst. 40: 1-16.

STOKEY, A.G. 1951. The contribution by the gametophyte to classification of the homosporous ferns. Phytomorphology 1(1,2): 39-58.

STOLZE, R.G. 1981. Ferns and fern allies of Guatemala, Part II Polypodiaceae. Fieldiana Bot. New Series (6): 1-210, 239-472, 515-522.

TRYON, R.M. 1964a. The ferns of Peru Polypodiaceae (Dennstaedtieae to Oleandreae). Contributions from the Gray Herbarium of Harvard University $n^{2}$ CXCIV. Cambridge. 253p.

TRYON, R.M. 1964b. Evolution in the leaf of living ferns. Bull. Torrey Bot. Club 21(5): 73-85.

TRYON,R.M. \& A.F. TRYON. 1982. Ferns and allied plants with special reference to Tropical America. Springer-Verlag. New York. 857p.

WAGNER Jr., W.H. 1952. Types of foliar dichotomy in living ferns. Am. J. Bot. 39(8): 578-592.

WINDISCH, P.G. \& M. PEREIRA-NORONHA. 1983. Notes on the ecology and development of Plagiogyria fialhoi. Am. Frern. J. 73(3): 79-84. 